\title{
Erratum to: HIV and Aging Research in Women: An Overview
}

\author{
David M. Stoff ${ }^{1} \cdot$ Deborah Colosi $^{1} \cdot$ Anna Rubtsova $^{2} \cdot$ Gina Wingood $^{3}$
}

Published online: 12 January 2017

(C) Springer Science+Business Media New York 2017

Erratum to: Curr HIV/AIDS Rep (2016) 13:383-391

DOI 10.1007/s11904-016-0338-4

The original version of this review article unfortunately contained mistakes in the References section. References $[59 \cdot \bullet$ ] and $[60 \cdot \bullet$ ] were mislabeled as published under Volume 13 of 2016 of Current HIV/AIDS Reports. These papers are still to be published under Volume 14 of 2017 of the Journal, thus, should be presented as below:

59.• Rubtsova AA, Kempf M-C, Taylor T, Konkle-Parker D, Wingood GM, Holstad MM. Healthy aging in older women living with HIV infection. Curr HIV/AIDS Rep. 2017;14. This paper reviewed psychosocial research among HIVinfected older women that occurred between 2013 and 2016 in the WIHS and elsewhere.

$60 . \bullet$ Thurn M, Gustafson D. Faces of frailty in aging with HIV infection. Curr HIV/AIDS Rep. 2017;14. This paper presented an overview of frailty definition and assessment and discussed how frailty is being studied in the WIHS.

The online version of the original article can be found at http://dx.doi. org/10.1007/s11904-016-0338-4.

David M. Stoff

dstoff@mail.nih.gov

National Institute of Mental Health, Bethesda, MD, USA

Emory University, Atlanta, GA, USA

3 Columbia University, New York, NY, USA 